\title{
Academic Change from Theory to Practice: Examples from an Engineering Faculty Development Institution
}

\section{Dr. John Ray Morelock, University of Georgia}

Dr. John Morelock recently graduated from Engineering Education at Virginia Tech as a recipient of the NSF Graduate Research Fellowship. His dissertation studied the teaching practices of engineering instructors during game-based learning activities, and how these practices affected student motivation. His research interests include engineering faculty development, student motivation, game-based teaching and learning, gamified classrooms, and engineering faculty collaborations around the scholarship of teaching and learning. He is currently the Associate Director for Educational Innovation and Impact at the University of Georgia's Engineering Education Transformations Institute.

\section{Dr. Joachim Walther, University of Georgia}

Dr. Joachim Walther is an Associate Professor of engineering education research at the University of Georgia and the Founding Director of the Engineering Education Transformations Institute (EETI) in the College of Engineering. The Engineering Education Transformations Institute at UGA is an innovative approach that fuses high quality engineering education research with systematic educational innovation to transform the educational practices and cultures of engineering. Dr. Walther's research group, the Collaborative Lounge for Understanding Society and Technology through Educational Research (CLUSTER), is a dynamic interdisciplinary team that brings together professors, graduate, and undergraduate students from engineering, art, educational psychology, and social work in the context of fundamental educational research. Dr. Walther's research program spans interpretive research methodologies in engineering education, the professional formation of engineers, the role of empathy and reflection in engineering learning, and student development in interdisciplinary and interprofessional spaces.

\section{Dr. Nicola W. Sochacka, University of Georgia}

Dr. Nicola Sochacka is the Associate Director for Research Initiation and Enablement in the Engineering Education Transformations Institute (EETI) in the College of Engineering at the University of Georgia. Her research interests include interpretive research quality, systems thinking, diversity, STEAM (STEM + Art) education, and the role of empathy in engineering education and practice. Her work has been recognized through multiple best paper awards and keynote presentations at international and national conferences and workshops. 


\title{
Academic change from theory to practice: Examples from UGA's Engineering Education Transformations Institute
}

\author{
Introduction
}

\begin{abstract}
Even early in the lifecycle of an academic change project, change agents may find that their relationship to change theory is far more complex than simply selecting a theory and translating it directly into practice. Change agents not only need to select change theories that align with their vision, but also to adapt the theory into a pragmatic framework to fit their social context and meet the myriad needs of administration, faculty, students, and other academic stakeholders. Further complicating use of theory in academic change projects is the substantial number of theoretical frameworks available that can be applied to academic change. These include frameworks that typologize different processoriented approaches to change (e.g., Henderson, Beach, \& Finkelstein, 2011; Van De Ven \& Poole, 1995) and theories that aim to identify contextual actors and relationships with the capacity to influence change, such as complex systems theory (Mason, 2009) and diffusion of innovations theory (Rogers, 2010). Fortunately, a variety of ways exist to integrate theory into a change project, lending great flexibility to change agents and reinforcing that there is no singular "correct" way to operationalize theory for academic change. This panelist paper illustrates the journey to-date of one early-stage change project's integration of theory to engender change by cultivating a teaching and learning community within an engineering college. This paper is accompanied by three other panelist papers detailing the integration of theory in academic change projects at different levels of maturity, along with an overarching panelist paper offering insights across panelists (Chan-Hilton, Morelock, Ingram, \& Utschig, 2019).

Our change project was the formation of the Engineering Education Transformations Institute (EETI), a faculty development and scholarship of teaching and learning (SOTL) arm of the College of Engineering at the University of Georgia (UGA). EETI was founded in early 2017 to promote and sustain a culture of engineering education scholarship and innovation that reaches across all programs in UGA's College of Engineering, which was founded in 2012. EETI has since partnered with several offices across campus to produce faculty-acclaimed programming that helps connect engineering faculty with their peers around the scholarship and practice of teaching and learning, and connect these faculty with the wider engineering education community. Examples of EETI's core programming include:
\end{abstract}

- Engineering education forums - Monthly seminars that bring faculty together to share ideas, hear from external presenters, and participate in activities to increase capacity around teaching and learning.

- SOTL incubator - Weekly meetings where EETI leadership helps faculty translate their scholarship of teaching and learning (SOTL) project ideas into opportunities for grant proposals and/or publications.

- Faculty learning communities - Biweekly meetings of faculty and EETI leadership to discuss and collectively learn from engineering education readings.

- Travel fellowships and research grants - EETI leadership provides resources to faculty to help them connect to the broader engineering education community at conferences, or pilot their SOTL project ideas. 
This paper examines how our use of frameworks derived from complex systems theory, in particular, has evolved over the course of EETI's development. A more comprehensive overview of EETI's formation, programming, and theoretical inspirations can be found elsewhere (Secules, Bale, Sochacka, \& Walther, 2018).

\section{Roles of theory in academic change projects: Our perspective}

In faculty development centers and programs, change among academic faculty is often used as a metric for a center or program's effectiveness (Plank \& Kalish, 2010). A plethora of research has explored organizational change processes but has remained largely divorced from academic change initiatives in practice (Henderson et al., 2011). Leveraging the theories emerging from organizational change literature could yield bountiful results in academic change projects moving forward, and use of theory is likely to play an important role in what Beach, Sorcinelli, Austin, and Rivard (2016) have dubbed the "Age of Evidence" in the field of faculty development, in which faculty developers are facing increasing pressure to demonstrate that their programming is effective in engendering change.

In our last publication on theory-to-practice efforts (Secules et al., 2018), we posited that use of theory in change efforts could be characterized by at least three roles that theory can play. First, theory use can be generative, in which theory is used a priori to guide the creation and continued development of a change project. Generative uses of theory include using theory as the basis for a change project's purpose, mission, values, activities, or evaluation criteria. Second, theory use can be pragmatic, in which theory is used to guide day-to-day project activities. For example, theory can inform how change agents handle dilemmas and roadblocks, how they navigate interactions with stakeholders, or in what directions they decide to expand and develop change projects. Third, theory use can be reflective, offering a lens through which to understand and communicate a change project's activity and story todate.

In our experience, the theories used in these three roles need not be identical. For example, change agents may find that one theory resonates as a way of generating a change project's initial structure, but find that another theory works better to pragmatically guide day-to-day practice. Moreover, change agents may find that the theory used to generate and direct a change project is difficult to use in communicating the change project's story to others, and thus may opt for a different theory to use reflectively.

In this paper, we will explore our use of theory in greater depth from all three perspectives. We will do so by focusing on how we used principles, ideas, and frameworks couched under the broad umbrella of complex systems theory.

\section{Complex systems theory: A brief description}

Complex systems theory-often called complexity theory-was developed at the intersection of several scientific and mathematical disciplines, notably computer science, theoretical physics, and ecology (Wolf-Branigin, 2013). It is heavily rooted in mathematics' chaos theory (Lewin, 1992), which asserts that even some deterministic systems (i.e., systems free of randomness) can be complex, behaving in ways that cannot be predicted across a long time horizon. This complexity arises because different elements in the system act upon one another in ways that cannot be precisely understood or modeled (Boeing, 2016). Nonetheless, it follows from chaos theory that such a system still tends to 
produce patterns of behavior that can be understood and leveraged to predict the system's trajectory. An early and accessible example of chaos theory in action is weather forecasting: Although humancreated models are able to predict weather patterns by up to two weeks with reasonable accuracy, the system of factors that influence weather is mathematically infeasible to model and predict with precision, despite being deterministic in nature (Boeing, 2016).

Complex systems theory diverges from chaos theory in that chaos theory seeks to explain why deterministic systems are able to change in unpredictable ways, while complex systems theory seeks to explain how the often numerous actors within a system interact with one another to engender change (Wolf-Branigin, 2013). According to Wolf-Branigin (2013) and Heylighen (2008), complex systems share at least three characteristics:

1. The system is self-organizing: Through interacting with one another, the actors within a system spontaneously (i.e., without direction from a centralized authority) arrange themselves to create a global system structure. In terms of organizational change, this means that change within an organization cannot be generated by a central authority, but rather must be championed and self-organized by the organization's members.

2. The system is emergent: Through self-organizing, systems develop behaviors and properties that could not be predicted by looking at the system's actors in isolation. In terms of organizational change, this means that system-level change occurs not through changing individual actors, but in creating ways for actors to interact and self-organize in new ways.

3. The system regulates itself through feedback: Interactions between actors create feedback loops that either reinforce certain system behaviors (positive feedback loop) or balance certain behaviors (negative feedback loops). In terms of organizational change, this means that effective change to a system behavior requires identifying and leveraging the aspects of the organization that reinforce or balance the behavior that one desires to change; simple causeand-effect assumptions will not suffice.

Although complex systems theory formally originated in the natural sciences and mathematics, it has gained substantial traction in social work and social sciences, where it has helped to explain social phenomena, advance inquiry into social systems, and offer avenues to engender change within those systems (Mason, 2009; Meadows, 2008; Wolf-Branigin, 2013). In our change project, we have used various recommendations and frameworks deriving from complex systems theory in the formation, operation, and communication of EETI's infrastructure.

\section{Generative Theory: Donella Meadows' Systems Thinking Framework}

EETI was founded by the authors in early 2017-shortly after the formation of UGA's College of Engineering-with the purpose of promoting and sustaining an organizational culture of engineering education scholarship and innovation within the growing College. Recognizing that organizations and their embedded cultures behave as complex systems (Frank \& Fahrbach, 1999; Svyantek \& Brown, 2000), we aimed to leverage complex systems theory as a means to enact cultural change around engineering education. Conceptually, this approach involved providing avenues for faculty to selforganize around discussions of engineering teaching and learning and create new feedback loops that promote continual engagement in conversations around engineering education scholarship and innovation. To translate that goal into practice, however, we needed a more concrete framework on 
which to base EETI's objectives and programming, and for that purpose, we turned to Donella Meadows' systems thinking framework (Meadows, 2008).

Donella Meadows was one of the foremost systems analysts in the field of environmental ecology in the late $20^{\text {th }}$ century, where she authored multiple landmark reports on the crises of exponential population growth and global environmental degradation, using complex systems theory to illustrate steps humanity could take to achieve sustainability (Meadows, Club of Rome, \& Potomac Associates, 1972; Meadows, Meadows, \& Randers, 1992; Meadows, Randers, \& Meadows, 2004). Envisioning that the ability to see the world in systems would be a crucial skill for understanding the world going forward, her final book-published posthumously-focused on helping readers comprehend properties of systems, think in terms of systems, and discern strategies to enact change within systems (Meadows, 2008). This book-and particularly the final chapter on strategies to engender change within systems-served as the basis for EETI's formation. In the book's final chapter, Meadows enumerates 14 principles that change agents can use to encourage change from within a system; we have described these principles in Appendix A. This section focuses on providing a few key examples of how we have leveraged Meadows' 14 principles in creating EETI.

EETI's primary mission was to allow faculty to self-organize and form new, positive relationships around the scholarship and practice of teaching and learning. To accomplish this mission, we sought to avoid remedial activities meant to help faculty "fix" their teaching practices, which the faculty development community has come to recognize as counterproductive to building a positive reputation among faculty (Haras, Ginsberg, Magruder, \& Zakrajsek, 2017). Rather, we drew from one of Meadows' principles, listen to the wisdom of the system, to adopt a strengths model of faculty development. Accordingly, our programming allows faculty to engage with EETI on their own terms, as EETI leadership adapts each semester's activities to reflect the existing interests and areas of expertise our faculty bring to the table. We were confident such an approach would resonate with a large swathe of faculty in our budding College of Engineering, as College administration built excellence in engineering education into the College's mission, and faculty hiring processes gave preference to candidates with an existing interest in undergraduate teaching and learning. Our efforts to understand the College's history, and its current values and practices around teaching and learning, arose from EETI leadership's commitment to another of Meadows' 14 principles: Get the beat of the system.

Meadows' 14 principles also guided our interactions with administration around EETI's formation, particularly in terms of defining our objectives and proposed evaluation metrics. We began by acknowledging one particular principle, expand time horizons, to recognize that our primary mission was to promote long-term cultural change around teaching and learning, rather than implementing short-term interventions with fleeting returns. Accordingly, we framed the official objectives of EETI around the idea of increasing shared social capacity around teaching and learning-i.e., forming relationships between faculty to enable new collaborations and build a community around teaching and learning. This focus on social capacity allowed us to define goals that were focused on people and cultures in a way that could be evaluated based on the diversity of participation (ensuring that new kinds of relationships are being formed) rather than simply the number of participants. This approach drew on two other Meadows' principles: Pay attention to what is important, not just what is quantifiable; and celebrate complexity. 


\section{Pragmatic Theory: Using the Principles to Adapt to Lessons Learned}

Applying Meadows' principles to EETI's mission and objectives was relatively straightforward, but applying them in practice took more self-reflection and discipline from EETI's leadership to learn from obstacles that arose and apply the appropriate principles to take action. Nonetheless, having a well-defined set of theoretical principles upfront has helped us to ensure that EETI remains true to its mission despite setbacks. This section illustrates two examples of obstacles that arose in the two years since EETI's founding, how Meadows' principles were used to address these obstacles, and lessons learned by EETI leadership in the process.

Lesson Learned \#1: Keeping faculty interests paramount requires self-reflection and discipline. Given that EETI was founded to leverage faculty strengths as a gateway to the teaching and learning community, it is important to EETI's mission that faculty interests and perspectives remain paramount in our programming. In some cases, keeping faculty interests paramount is as straightforward as sending out a regular survey to gauge ideas for topics in which faculty are interested (following from another of Meadows' principles, stay humble - stay a learner.) However, there have been some situations in which we (EETI leadership) have struggled to suspend our own interests and desires that may not align with those of faculty.

For example, one of our programs is a research incubator in which faculty can partner with EETI leadership to help translate an idea for a scholarship of teaching and learning (SOTL) project into a grant proposal or publishing opportunity. Because EETI leadership is directly involved with the development of these ideas, we often become invested in and excited about new projects alongside the faculty with whom we work. While many of these projects have proceeded smoothly, in other cases, faculty working in the incubator become overloaded in their roles and reprioritize their commitments, causing them to temporarily or permanently abandon their SOTL projects. In these situations, we are often tempted to pick up where the faculty member(s) left off and continue developing the grant proposal or publication. However, doing so would conflict with one of Meadows' principles: Go for the good of the whole. Continuing to advance the project in absence of the faculty member(s) takes away from time we could be spending to help other faculty members develop, ultimately detracting from our efforts as a whole. Accordingly, we have developed skills in self-reflection to recognize when our interests conflict with those of faculty, and in self-discipline to ensure that our desires do not compromise the systemic change initiatives for which we created EETI.

Lesson Learned \#2: Assessing less tangible outcomes is important, but requires creative solutions. Since EETI's founding, we have anecdotally noticed an increase in excitement around engineering teaching and learning, culminating in greater connectedness between our engineering faculty and greater initiative to seek out teaching and learning professional development opportunities. In keeping with our theoretical foundations and mission, we consider these outcomes to be of the utmost importance. While headcounts at EETI's events tell part of this story from an assessment standpoint, they do not sufficiently capture the shift in culture we have seen, nor should they be considered the end-all-be-all measure for the effectiveness of faculty development activites (Plank \& Kalish, 2010). Rather, the nature of relationships between faculty members is difficult to quantify or qualitatively communicate in a way that is accessible to multiple stakeholder audiences. Nonetheless, one of Meadows' principles- Pay attention to what is important, not just what is quantifiable-tells us that assessing those relationships is vital to long-term systemic change. Accordingly, we are looking toward new assessment techniques to better capture the connectedness among our engineering faculty 
as a result of EETI. We are presently exploring social network analysis as a means to conduct such an evaluation.

\section{Reflective Theory: Using permaculture as a metaphor}

While we find Donella Meadows' 14 principles useful to guide EETI's creation and operation, we also find that it is difficult to articulate an overarching narrative that ties these 14 principles together. Therefore, while they are great tools to explicate the reasoning behind decisions we have made as part of EETI, they are suboptimal to communicate EETI's overall philosophy and narrative. For such communication purposes, we prefer to use the metaphor of permaculture, a systems thinking design approach from the discipline of ecological design.

Originally proposed in the late 1970s by Mollison and Holmgren (1978) and further developed as an idea in the 1990s, permaculture is a set of design principles with an original goal of creating selfsustaining human agriculture (Holmgren, 2002). It is commonly used today as an approach to homescale gardening (Hemenway, 2009). As Hemenway $(2009$, p. 5) articulates, the overarching goal of permaculture is to "focus less on the objects themselves than on the careful design of relationships among them-interconnections - that will create a healthy, sustainable whole. These relationships are what turn a collection of unrelated parts into a functioning system, whether it's a backyard, community, or an ecosystem."

We find that many examples of how the permaculture applies to garden systems work surprisingly well as analogies for describing how systems thinking applies to social systems. For example, permaculture asserts that every cycle of gardening produces energy that can be harnessed and reinvested to yield more fertile soil for the next cycle of gardening, even if initial yields fall below expectations. Similarly, the perspective of EETI's leadership (from complex systems theory) posits that faculty development activities each semester that get faculty interacting with one another around teaching and learning create a richer network of relationships that can yield tangible impacts in future semesters, even if those activities do not directly produce any new projects around teaching and learning. As another example, permaculture asserts that optimal gardening occurs when gardeners identify leverage points that are most receptive to interventions, allowing a change to the garden ecosystem for minimal effort. Similarly, EETI leverages those faculty who already have a passion for teaching and learning (often instructional faculty) to initiate engineering education projects, and to share their projects with their peers to generate a greater level of interest in the broader faculty community.

We find that reflective use of theory is something that evolves over time. For example, we initially thought to use permaculture as a means to explain all of EETI's decisions, but we found that Meadows' 14 principles are still more effective as explanatory tools, as they more directly connect to complex systems theory, which was central to EETI's foundation. As time goes on, we will likely discover new uses for Meadows' 14 principles and permaculture in communicating EETI to various audiences, and may even come across a new theory with even more robust reflective uses.

\section{Conclusion}

EETI's relationship to the complex systems theory of change has been complex and frequently evolving, but we believe that our journey can yield at least three useful takeaways for other faculty developers looking to engender academic change. First, theory can have a multitude of different uses 
throughout a change project, including establishing a project's mission and values, guiding operations, helping change agents to overcome obstacles, and communicating one's change project to others. Second, a single theory or framework need not define the whole of one's change project; change agents may find it useful to leverage different theories (or different aspects of a single theory, as was our case) for different purposes (i.e., generative, pragmatic, or reflective.) Third, having a set of principles or guiding philosophy derived from theory is essential to ensure that a change project's mission is successfully realized amid the many roadblocks change agents can face in practice. If you are an acting or aspiring academic change agent, we encourage you to seek a theory of change that fits with your goals, values, and context, and to use that theory to guide the formation and execution of your project. Complex systems theory, with its broad applicability and interdisciplinary roots, may be a good place to start.

\section{References}

Beach, A. L., Sorcinelli, M. D., Austin, A. E., \& Rivard, J. K. (2016). Faculty Development in the Age of Evidence: Current Practices, Future Imperatives. Sterling, VA: Stylus Publishing.

Boeing, G. (2016). Visual Analysis of Nonlinear Dynamical Systems: Chaos, Fractals, Self-Similarity and the Limits of Prediction. Systems, 4(4), 37.

Chan-Hilton, A., Morelock, J. R., Ingram, E., \& Utschig, T. (2019). Connecting Theory with Practice: Four Change Projects in Faculty Development for Engineering. Paper presented at the ASEE Annual Conference \& Exposition, Tampa, FL.

Frank, K. A., \& Fahrbach, K. (1999). Organization Culture as a Complex System: Balance and Information in Models of Influence and Selection. 10(3), 253-277. doi:10.1287/orsc.10.3.253

Haras, C., Ginsberg, M., Magruder, E. D., \& Zakrajsek, T. (2017). A Beta Faculty Development Center Matrix. Retrieved from https://www.acenet.edu/news-room/Documents/A-Beta-FacultyDevelopment-Center-Matrix.pdf. Archived at https://perma.cc/7QUD-ERR2

Hemenway, T. (2009). Gaia's Garden: A Guide to Home-Scale Permaculture, 2nd Edition. White River Junction, VT: Chelsea Green Publishing.

Henderson, C., Beach, A., \& Finkelstein, N. (2011). Facilitating change in undergraduate STEM instructional practices: An analytic review of the literature. Journal of Research in Science Teaching, 48(8), 952-984. doi:https://doi.org/10.1002/tea.20439

Heylighen, F. (2008). Complexity and self-organization. In M. J. Bates \& M. N. Maack (Eds.), Encyclopedia of Library and Information Sciences (3rd ed., pp. 1215-1224). London: Taylor \& Francis.

Holmgren, D. (2002). Permaculture: Principles \& Pathways Beyond Sustainability: Holmgren Design Services.

Lewin, R. (1992). Complexity : life at the edge of chaos. New York Macmillan Pub. Co.

Mason, M. (2009). What is complexity theory and what are its implications for educational change? In M. Mason (Ed.), Complexity Theory and the Philosophy of Education (pp. 32-45): Wiley.

Meadows, D. H. (2008). Thinking in Systems: A Primer (D. Wright Ed.). White River Junction, VT: Chelsea Green Publishing.

Meadows, D. H., Club of Rome, \& Potomac Associates. (1972). The Limits to growth: a report for the Club of Rome's project on the predicament of mankind: Universe Books.

Meadows, D. H., Meadows, D. L., \& Randers, J. (1992). Beyond the Limits: Confronting Global Collapse, Envisioning a Sustainable Future: Chelsea Green Pub.

Meadows, D. H., Randers, J., \& Meadows, D. L. (2004). Limits to Growth: The 30-Year Update: Chelsea Green Publishing. 
Mollison, B. C., \& Holmgren, D. (1978). Permaculture One: A perennial agricultural system for human settlements. Melbourne, Australia: Transworld Publishers.

Plank, K. M., \& Kalish, A. (2010). Program assessment for faculty development. In K. J. Gillespie \& D. L. Robertson (Eds.), A Guide to Faculty Development : Practical Advice, Examples, and Resources (pp. 135-149). San Francisco, CA: Wiley.

Rogers, E. M. (2010). Diffusion of Innovations (4th Ed.): Free Press.

Secules, S., Bale, J. J., Jr., Sochacka, N. W., \& Walther, J. (2018). Examining a Novel Theory-to-practice Effort in Engineering Education through Multiple Theoretical Lenses of Systems and Change. Paper presented at the 2018 ASEE Annual Conference \& Exposition, Salt Lake City, UT.

Svyantek, D. J., \& Brown, L. L. (2000). A Complex-Systems Approach to Organizations. 9(2), 69-74. doi:10.1111/1467-8721.00063

Van De Ven, A. H., \& Poole, M. S. (1995). Explaining Development and Change in Organizations. Academy of Management Review, 20(3), 510-540. doi:10.5465/AMR.1995.9508080329

Wolf-Branigin, M. (2013). Introduction: The History and Theory of Complexity. In M. Wolf-Branigin (Ed.), Using Complexity Theory for Research and Program Evaluation. Oxford: Oxford University Press. 
Appendix A: 14 principles for engineering change from within a system (Meadows, 2008)

\begin{tabular}{|c|c|}
\hline Principle & Description of Principle \\
\hline Get the beat of the system & $\begin{array}{l}\text { Understand the system's history and how it works before } \\
\text { attempting to change it. }\end{array}$ \\
\hline $\begin{array}{l}\text { Expose your mental models to } \\
\text { the light of day }\end{array}$ & $\begin{array}{l}\text { Frequently express and evaluate how you understand the system } \\
\text { to operate. }\end{array}$ \\
\hline $\begin{array}{l}\text { Honor, respect, and distribute } \\
\text { information }\end{array}$ & $\begin{array}{l}\text { Information exchanges control system operation, so disclose } \\
\text { information truthfully and promptly to keep the system running } \\
\text { smoothly. }\end{array}$ \\
\hline $\begin{array}{l}\text { Use language with care and } \\
\text { enrich it with system concepts }\end{array}$ & $\begin{array}{l}\text { The language used by system actors signifies what behaviors are } \\
\text { valued within the system. Consistently use language that aligns } \\
\text { with desired system behavior. }\end{array}$ \\
\hline $\begin{array}{l}\text { Pay attention to what is } \\
\text { important, not just what is } \\
\text { quantifiable }\end{array}$ & $\begin{array}{l}\text { Measures often become targets. Assess what is important, and } \\
\text { system actors will strive to improve accordingly. }\end{array}$ \\
\hline $\begin{array}{l}\text { Make feedback policies for } \\
\text { feedback systems }\end{array}$ & $\begin{array}{l}\text { Create policies that dynamically change in response to the system } \\
\text { to create balancing loops and avoid undesirable positive feedback } \\
\text { loops. }\end{array}$ \\
\hline Go for the good of the whole & Seek to optimize the whole system, rather than individual parts. \\
\hline $\begin{array}{l}\text { Listen to the wisdom of the } \\
\text { system }\end{array}$ & $\begin{array}{l}\text { Recognize the value that already exists in the system and } \\
\text { encourage it. Don't try to overthrow behaviors that help the } \\
\text { system run smoothly. }\end{array}$ \\
\hline $\begin{array}{l}\text { Locate responsibility in the } \\
\text { system }\end{array}$ & $\begin{array}{l}\text { Ensure that actors in the system get swift feedback about the } \\
\text { consequences of their own behavior. }\end{array}$ \\
\hline Stay humble - Stay a learner & $\begin{array}{l}\text { Seek to constantly learn about the system. Check-don't } \\
\text { assume-that your interventions are helping. }\end{array}$ \\
\hline Celebrate complexity & $\begin{array}{l}\text { Embrace the system instead of trying to force change. Encourage } \\
\text { diversity, self-organization, and disorder. }\end{array}$ \\
\hline Expand time horizons & Seek long-term benefits rather than short-term gains. \\
\hline Defy the disciplines & $\begin{array}{l}\text { Systems often stretch across disciplinary lines. Learning about and } \\
\text { changing a system requires crossing those lines and taking an } \\
\text { interdisciplinary approach. }\end{array}$ \\
\hline Don't erode the goal of goodness & $\begin{array}{l}\text { Cynicism in system actors breeds poor system performance. } \\
\text { Uphold system ideals and maintain high expectations for system } \\
\text { actors. }\end{array}$ \\
\hline
\end{tabular}

